\title{
Optimization of Liquefied Petroleum Gas (LPG) Distribution in Nigeria
}

\author{
Ihemtuge, T.U and Aimikhe, V.J
}

\begin{abstract}
As the clamor for cleaner energy sources continues, it becomes imperative to increase the per capita consumption rate of LPG, especially in developing countries like Nigeria, where the dependency on fuelwood for cooking and heating purposes, is very high. To achieve this, efforts must be made to increase the availability of the commodity while reducing its cost. Several factors are responsible for the low per capita consumption rate of LPG in Nigeria, among which are the inadequate distribution network, which not only makes the product unavailable but also expensive when available. This study focused on optimizing the LPG distribution network in fourteen major cities across Nigeria to reduce the overall landing interstate cost of the commodity. This was achieved by the application of an optimization program on existing and two (2) new proposed distribution outlets to minimize the trucking cost using the volume of LPG, distance and time between bulk terminals and various city locations across the country, as variables. The results of the model showed that the LPG loading and distribution from the proposed outlets reduced the cost of trucking of LPG by an average of $25 \%$. This is expected to reduce the landing cost of LPG further and consequently lead to an increase in the per capita consumption of LPG in the country.
\end{abstract}

Index Terms - Clean energy, LPG distribution, optimization, trucking cost.

\section{INTRODUCTION}

Liquefied Petroleum Gas (LPG) is a generic term used to describe a mixture of hydrocarbons having three or four carbon atoms. LPG is also known as LP-gas or cylinder gas. It is one of the cleanest fossil fuels available to domestic, commercial, and industrial users.

LPG is a colorless, highly flammable, and odorless gas. It is non-toxic but, if inhaled in considerable quantities over a prolonged period, can have an anesthetic effect. Its physical properties depend on its composition. LPG has a typical specific calorific value of $46.1 \mathrm{MJ} / \mathrm{kg}$. Relative density varies between 0.50-0.52 for propane and 0.56-0.59 for butane. Liquefied petroleum gases are quite safe in comparison with other fuels. For instance, Propane has a high ignition temperature of about $850-950{ }^{\circ} \mathrm{F}\left(450-510{ }^{\circ} \mathrm{C}\right)$, compared to about $495{ }^{\circ} \mathrm{F}\left(257^{\circ} \mathrm{C}\right)$ for gasoline [1], making it less likely to ignite spontaneously.

LPG, as marketed in most countries rarely, consists of pure propane or butane. It is mostly a mixture of liquefiable saturated and unsaturated hydrocarbons in the $\mathrm{C}_{3}-\mathrm{C}_{4}$ boiling range. The actual gas mixture varies depending on whether

Ihemtuge, Tochukwu Uzoma, Department of Petroleum and Gas Engineering, University of Port Harcourt, Nigeria, +234-8032625505.

Aimikhe, Victor Joseph, Department of Petroleum and Gas Engineering, University of Port Harcourt, Nigeria, +234-8169558835. the LPG is produced from refinery gases or associated gas, i.e., gas produced with crude oil or coming from a gas field. However, LPG is sold commercially to domestic and industrial customers in three (3) grades [2], namely:

- $L P G$ - butane/commercial butane consisting mainly of n-butane, isobutane, and the butylenes.

- $L P G$ - propane/commercial propane consisting mainly of propane and propylene. In colder countries such as Norway and Sweden, the LPG market is primarily confined to propane.

- $\quad$ PPG mixture consisting of a variable amount of all $\mathrm{C}_{3} / \mathrm{C}_{4}$ hydrocarbons.

\section{A. LPG Consumption}

LPG consumption in households is increasing throughout the world, especially in the Asia Pacific region, due to the region's vast and widespread population base. Increasing gas imports and rising demand for cleaner fuels, mainly from large emerging economies such as India and China, are expected to fuel global gas consumption soon. Another critical factor for LPG consumption growth is the adverse environmental effect of using biomass and kerosene. Studies have shown that black carbon, which is mostly "soot," formed in the combustion of wood and fuel such as diesel and kerosene, is the second most important contributor to global climate change [3]. Several other studies have shown that inefficient and traditional utilization of biomass fuel and kerosene have severe health implications such as the risk of low birth weight and pulmonary tuberculosis, productivity, and the environment. According to a report by the International Society for Environmental Epidemiology [4], the risk associated with air pollution from solid fuels accounts for 3 percent of global losses of health risk. Statistically, about 1.3 million people, mostly women, and children die prematurely every year from exposure to indoor air pollution from biomass.

As a result of the human and environmental consequences of using fuelwood and kerosene for domestic applications, there has been a significant increase in LPG demand, mainly in the domestic and commercial sectors, due to the switching of local consumers from biomass to LPG, mostly in India, Indonesia and other developing countries like Nigeria. In Nigeria, for instance, LPG consumption has witnessed a steady growth from 130,000 metric tons in the year 2011, 145,000 metric tons in 2012, 250,000 metric tons in 2013, 500,000 metric tons in 2016, and expected to rise to $2,000,000$ metric tons in the coming years [5]. 
Despite these improvements in LPG consumption over the years, the consumption capacity still stands at about $15 \%$ of the total LPG produced per annum. Consequently, despite the country being rich in Natural gas and also a leading exporter of LPG in Africa, it still has one of the lowest per capita LPG consumption rates in Africa (South Africa, $5.5 \mathrm{~kg}$ and Morocco, $44 \mathrm{~kg}$ ) with its per capita consumption rate put at $1.8 \mathrm{~kg}$, compared to the West African average of $3.5 \mathrm{~kg}$ [5]. This low consumption rate can be attributed to reports that over $80 \%$ of the Nigerian population relies on the use of biomass fuels for cooking [6]. Fuelwood and charcoal have primarily been known to be the significant sources of energy for cooking and heating needs purposes, especially for people in rural areas. At the same time, kerosene is mostly used in urban areas. The preference for biomass fuel and kerosene among primarily poor people in Nigeria is mainly due to factors such as:

- Affordability,

- Availability

- Awareness and Safety.

If these factors can be eliminated, up to $69 \%$ of non-users in the country can be converted to using LPG [7]. Other factors, such as cultural beliefs, price, and insufficient infrastructure and logistics challenges [8], have also been identified as some of the factors influencing demand for LPG. The LPG market responds to market changes in the international oil and LNG prices; hence an increase in the global price of LPG affects domestic consumptions as consumers tend to move down the energy chain towards other energy alternatives. However, there are arguments that consumers might continue to make purchases based on the habit, even if prices reduce [9].

\section{B. LPG Domestic Production and Supply}

LPG was first produced at the Kaduna refinery and subsequently to all the four refineries in Nigeria. However, with the operational bottlenecks of the refineries and the subsequent establishment of Nigerian Liquefied Natural Gas (NLNG $\}$ in 1999, the company was tasked with the production of LPG both for domestic and exportation. Hence it is the major supplier of LPG to the Nigerian domestic market. Manufacture and supply of LPG are basically from Gas processing, importation, and oil refineries. The bulk of this production comes from gas processing from major international oil companies and the NLNG, which has been able to stabilize domestic supply in recent times [5]. Production from refineries has been reported to be very low and insignificant compared to other sources [10]. Various other studies have been published for possible and viable sources of LPG production in Nigeria. LPG production from flare gas outlets across the country is both technically and economically feasible [11] - [13].

\section{LPG Safety}

There is usually a great feeling of insecurity concerning LPG safety issues. A fear about explosions is a concern raised by many people about hazards and indoor air pollution effects. This perception has also contributed to the low consumption rate of LPG within the country as most people see the LPG as a highly risky source of energy; hence, they do not use it even when it is readily available. These assertions are not far from the truth as there have been several fire incidents resulting from the use of LPG. Amongst the factors responsible for these fire incidents associated with the use of LPG include:

- Use of sub-standard LPG accessories

- Over pressurizing of gas cylinders

- Lack of adequate and regular inspection and maintenance of containment devices and accessories.

To prevent these fire accidents, there is a need for more enlightenment of the citizens, especially in the rural areas. This, along with all the stakeholders, resolve to stamp out substandard LPG accessories that will help in improving safety.

LPG leak detection devices have been developed to reduce the occurrence of fire outbreak during leakages. One of such methods is a proprietary device designed by using sudden pressure drop and rise in gas concentration to set off an alarm system, which can enable a manual or automatic shutdown of the gas supply. Gas leak detection devices have also been designed to shut down the supply of gas in the event of a leak, thereby preventing the explosion [14]. The causes of explosions emanating from gas leaks as a result of structural failure - be it due to creep, fatigue, fire-induced, or other forms of accidental jeopardy, have been reported in the literature [15],[16]. The Safe handling practices of LPG storage tanks and cylinders have also been widely reported [17]-[21].

\section{LPG Distribution in Nigeria}

Liquefied petroleum gas exists either as a gas (vapor) or liquid when it is under a modest amount of pressure in gas bottles, cylinders, tanks, and larger LPG storage vessels. Given that gaseous LPG has a volume 270 times that of liquid LPG, it is almost always transported in its more compact liquid state. Liquefied petroleum gas can be conveyed in many ways, including by ship, rail, tanker trucks, intermodal tanks, cylinder trucks, pipelines, and local gas reticulation systems [22]. Liquefied petroleum gas pipelines are typically employed between gas fields and storage terminals. The prohibitive expense involved in building pipelines makes them rare for LPG transportation.

LPG intra-state or inter-state distribution in Nigeria is mainly by road, with the use of Bridger or Bobtail trucks. The biggest challenge facing the LPG sector in Nigeria is distribution logistics [5]. The inadequate distribution facilities ranging from small low draft vessels, channel draft restrictions, scarce receiving terminals, inadequate transportation infrastructure, insufficient cylinder manufacturing plant, inadequate secondary bulk storage facilities [23] among other challenges, have hampered the smooth distribution and as a result, contributed to an increase in the landing cost of the commodity in the country.

Currently, the leading producer of LPG in Nigeria is Nigeria Liquefied Natural gas (NLNG) in its bonny plant. 
After production in Bonny, the LPG is transported to Lagos, where the operational storage facilities are located. From this storage terminal, the haulage tankers from different parts of the country will load and supply to the dispensing stations across the country. This movement of the commodity from Finima, Bonny (Rivers State) to Atlas Cove in Lagos for storage before distribution to other parts of the country, creates a bottleneck, which makes LPG landing cost expensive. Also, the imported LPG volumes are discharged at the Lagos facility, from where it is distributed. Although there are LPG storage facilities in the coastal cities of Port Harcourt and Calabar, the facility in Port Harcourt was only commissioned recently. At the same time, the facility in Calabar is barely functional. It remains to be seen whether these facilities would be fully operational in the coming years. Fig. 1 shows the current LPG distribution network in Nigeria, with a single functional distribution outlet in Lagos to all parts of the country. The shaded areas on the map are the locations of the three (3) refineries were very little LPG is produced.

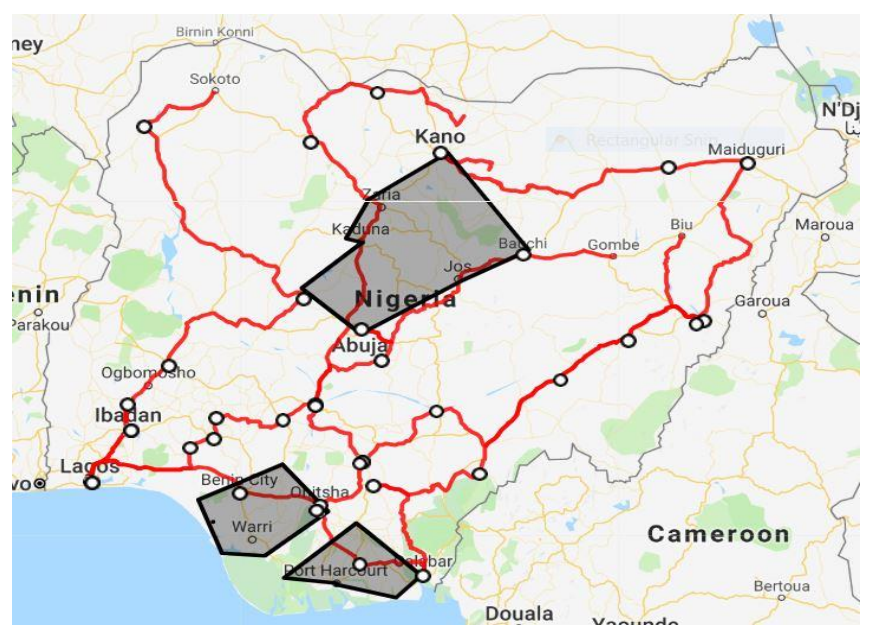

Fig.1. Current Distribution Network of LPG in Nigeria

This study aims to develop a new cost-effective distribution network for the inland distribution of LPG in Nigeria, using a minimization routine. The proposed storage facilities at Finima and Calabar will serve as distribution outlets to end-users. This study leverages the already existing platforms and jetty presently available at these proposed locations hence eliminating the cost of building new structures that would significantly increase the cost of the project. This study will also develop a model, which will be used to determine the minimum price of trucking LPG across the selected cities. This model will then be used to determine if the proposed distribution channels will be cost-effective when compared with the existing distribution channel. Emphasis is on fourteen (14) major cities across the country.

The optimization model development is aimed at reducing the landing cost of LPG across the country, thus contributing significantly to the increase in the per capita consumption of LPG. Asides making LPG readily available and at a reduced cost in Nigeria, there will also be a reduction in the environmental pollution caused by the inefficient use of biomass as a primary source of cooking energy.

\section{MODEL DEVELOPMENT}

To fully optimize the distribution of LPG in-country, two distribution channels are proposed in Port Harcourt and Calabar, which will leverage already existing structures, thereby reducing the cost of setting up new avenues. The proposed distribution channels and the existing one in Lagos were evaluated using a non-linear optimization routine to determine the optimal distribution channel. In doing this, the following parameters were assessed:

- Time taken to transport LPG from Atlas cove to the selected States.

- Distance between Atlas cove and the selected States

- The unit cost of trucking LPG to the states

- The LPG truck volume.

Using data from Table A1 of Appendix A, an optimization model was proposed. The model is of the form:

Minimize

$$
C=k_{1} x_{1}+k_{2} x_{2}+k_{3} x_{3}
$$

Where $\mathrm{C}$ is the trucking cost, $x_{1}, x_{2}$, and $x_{3}$ are the independent variable (distance $(\mathrm{km})$, time (hour), and volume tons).

In the first instance, a non-linear optimization program was used to model the data, but it failed to converge, and as such, no solution was obtained. This non-convergence is because the dependent and independent variables are linearly related. Hence a linear program of the form in Eq. 2 was developed.

\section{Minimize}

$$
C=k_{1} x_{1}+k_{2} x_{2}+k_{3} x_{3}+\cdots+k_{n} x_{n}+0 s_{1}+0 s_{2}+0 s_{3}+\cdots+0 s_{n}
$$

\section{Subject to:}

$$
\begin{aligned}
& a_{11} x_{1}+a_{12} x_{2}+a_{13} x_{3}+\cdots+a_{1 n} x_{n}+s_{1}=b_{1} \\
& a_{21} x_{1}+a_{22} x_{2}+a_{23} x_{3}+\cdots+a_{2 n} x_{n}+s_{2}=b_{2} \\
& a_{31} x_{1}+a_{32} x_{2}+a_{33} x_{3}+\cdots+a_{3 n} x_{n}+s_{3}=b_{3} \\
& a_{m 1} x_{1}+a_{m 2} x_{2}+a_{m 3} x_{3}+\cdots+a_{m n} x_{n}+s_{n}=b_{n}
\end{aligned}
$$

$$
\text { For }
$$

$$
k_{i}, x_{i}>0 \text {, where } i=1,2,3 \text {, }
$$

Where $k i$ is the coefficient of the variables, $x i$. Si is slack variables with coefficient zero (0). $b i$ are constants. Reducing Eq 2 to Eq.3, the model becomes:

Minimize

$$
C=k_{1} x_{1}+k_{2} x_{2}+k_{3} x_{3}+0 s_{1}+0 s_{2}+0 s_{3}
$$




$$
\begin{aligned}
& a_{11} x_{1}+a_{12} x_{2}+a_{13} x_{3}+s_{1}=b_{1} \\
& a_{21} x_{1}+a_{22} x_{2}+a_{23} x_{3}+s_{2}=b_{2} \\
& a_{31} x_{1}+a_{32} x_{2}+a_{33} x_{3}+s_{3}=b_{3} \\
& \text { for } \\
& k_{i}, x_{i}>0 \text {, where } i=1,2,3, \ldots, n
\end{aligned}
$$

where

$$
\begin{gathered}
k \text { is the } k_{i}(i=1,2,3) \\
A=\left[\begin{array}{lll}
a_{11} & a_{12} & a_{13} \\
a_{21} & a_{22} & a_{23} \\
a_{31} & a_{32} & a_{33}
\end{array}\right]
\end{gathered}
$$

and

$$
b=\left[\begin{array}{l}
b_{1} \\
b_{2} \\
b_{3}
\end{array}\right], s
$$

Assuming a typical LPG truck carries 21 metric tons of LPG, and using the data in Table A1, of Appendix A, then;

$$
b=\left[\begin{array}{l}
750000 \\
700000 \\
720000
\end{array}\right]
$$

and

$$
A=\left[\begin{array}{ccc}
1782 & 29.0 & 21 \\
1144 & 16.08 & 21 \\
1609 & 22.1 & 21
\end{array}\right]
$$

A MATLAB program was used to solve the linear programming model of Eq.3 using the Simplex Method. The solution to the model was obtained as:

$$
C=30698 x_{3}+4841 x_{2}-19.66 x_{1}
$$

\section{Where}

$x_{3}$ is the volume of LPG (metric tons) transported, the unit of the coefficient is cost per metric ton transported

$x_{2}$ is the time (hour) traveled, the unit of the coefficient is cost per hour traveled

$x_{1}$ is the distance $(\mathrm{km})$ from source to destination, the unit of the coefficient is cost per km traveled.

For this study, some factors which can affect the time of travel were kept constant during the optimization process. These factors are:

- The conditions of the road.

- The Nature and condition of the trucks.

- Stoppages along the road due to gridlocks and other factors

\section{RESULTS AND DISCUSSION}

The result of the optimization routine is presented in Table 1. From the results, the minimization routine has reduced the trucking costs of LPG using specific distribution outlets, as against the current trend of using only the Lagos distribution outlet. For example, the current trucking cost for moving LPG from Lagos to Akure is one hundred and thirty-five thousand naira $(\$ 135,000)$. However, the result from the model showed that this could be reduced to ninety-three thousand, one hundred and three-naira forty-five kobo ( $\$ 93,103.45)$. Also, the proposed distribution routes were subjected to the optimization model. The results from the model showed that distributing LPG from the proposed Port Harcourt channel to Kano and Sokoto is more cost-effective with a cost reduction of $24 \%$, respectively, than transporting LPG from Lagos as is currently the case. Also, it is more profitable to distribute LPG from Calabar to Gombe and Maiduguri, with an average cost reduction of $28 \%$ and $25 \%$, respectively, than from Lagos.

The results also showed the most cost-effective distribution outlets for LPG transportation to specific cities across the country. For instance, Figs 2 and 3 show the preferred cities for LPG distribution from the proposed Calabar and Port Harcourt distribution outlets, respectively. It should be noted that LPG distribution to the town of Enugu, can either be from the Port Harcourt or the Calabar outlets, due to the similarity in cost of trucking.

Also, the Lagos distribution outlet was more cost-effective for LPG distribution to cities in the southwest region like Lagos (where the current distribution outlet is located), Akure and Ibadan, due to the proximity to the Lagos distribution outlet. The LPG distribution network from the Lagos distribution outlet remains strategic and essential for the distribution of the commodity to cities closer to the Lagos distribution outlet, as shown in Fig 1. Similarly, the delivery from the refineries to cities around them is also vital. Also, two (2) new proposed distribution networks form the Port Harcourt and Calabar outlets, obtained from the optimization model, has been developed. These proposed distribution outlets, together with the Lagos outlet and refineries, will help drive down the delivery cost of LPG across the country. Fig.4 shows the new distribution networks. 
International Journal of Engineering and Technical Research (IJETR)

ISSN: 2321-0869 (O) 2454-4698 (P), Volume-10, Issue-5, May 2020

Table 1. Optimized and current trucking cost of the selected routes.

\begin{tabular}{|c|c|c|c|c|c|c|c|}
\hline Cities & $\begin{array}{c}\text { Distance } \\
\text { from Lagos } \\
(\mathbf{K m})\end{array}$ & $\begin{array}{c}\text { Current } \\
\text { Trucking Cost } \\
\text { (\#) }\end{array}$ & $\begin{array}{c}\text { Minimized } \\
\text { Cost using } \\
\text { Lagos Route }\end{array}$ & $\begin{array}{c}\text { Distance } \\
\text { from Port } \\
\text { Harcourt } \\
(\mathbf{K m})\end{array}$ & $\begin{array}{c}\text { Minimized } \\
\text { Cost using Port } \\
\text { Harcourt } \\
\text { Route }\end{array}$ & $\begin{array}{c}\text { Distance } \\
\text { from } \\
\text { Calabar } \\
(\mathbf{K m})\end{array}$ & $\begin{array}{c}\text { Minimized Cost } \\
\text { using Calabar } \\
\text { Route } \\
\end{array}$ \\
\hline
\end{tabular}

(¥)

\begin{tabular}{|c|c|c|c|c|c|c|c|}
\hline Akure & 314 & 135,000 & 93,103 & 473 & 243,000 & 625 & 256,500 \\
\hline Awka & 501 & 300,000 & 285,714 & 213 & 214,285 & 289 & 240,000 \\
\hline Bauchi & 1284 & 710,000 & 676,190 & 915 & 514,493 & 829 & 489,655 \\
\hline Enugu & 560 & 280,000 & 266,667 & 226 & 202,899 & 259 & 200,000 \\
\hline Gombe & 1291 & 700,000 & 666,667 & 1070 & 507,246 & 984 & 482,758 \\
\hline Ibadan & 139 & 106,000 & 73,103 & 594 & 125,080 & 625 & 132,500 \\
\hline Kano & 1063 & 700,000 & 666,667 & 1004 & 507,246 & 1022 & 608,695 \\
\hline Maiduguri & 1589 & 720,000 & 685,714 & 1363 & 580,645 & 1148 & 514,285 \\
\hline Makurdi & 744 & 550,000 & 523,809 & 488 & 482,456 & 415 & 440,000 \\
\hline Owerri & 534 & 350,000 & 333,333 & 95 & 250,000 & 206 & 280,000 \\
\hline $\begin{array}{c}\text { Port } \\
\text { Harcourt }\end{array}$ & 616 & 400,000 & 380,952 & N/A & N/A & N/A & N/A \\
\hline Sokoto & 1782 & 750,000 & 714,285 & 1233 & 543,478 & 1305 & 652,173 \\
\hline Umuahia & 577 & 360,000 & 342,857 & 115 & 255,319 & 155 & 288,000 \\
\hline Uyo & 656 & 500,000 & 476,190 & 141 & 403,225 & 88 & 344,827 \\
\hline
\end{tabular}

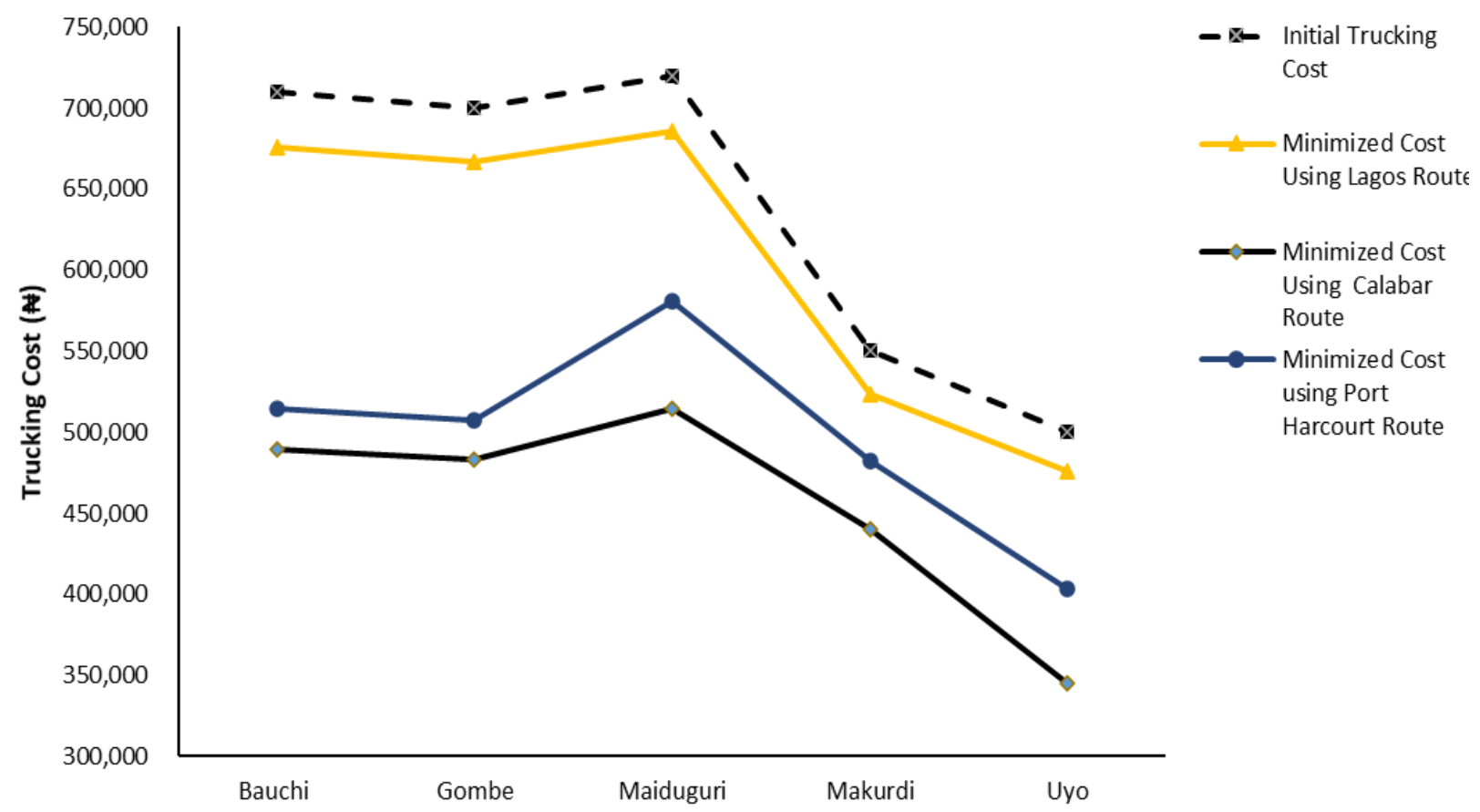

City

Fig.2. Preferred Cities for Calabar Distribution Outlet 


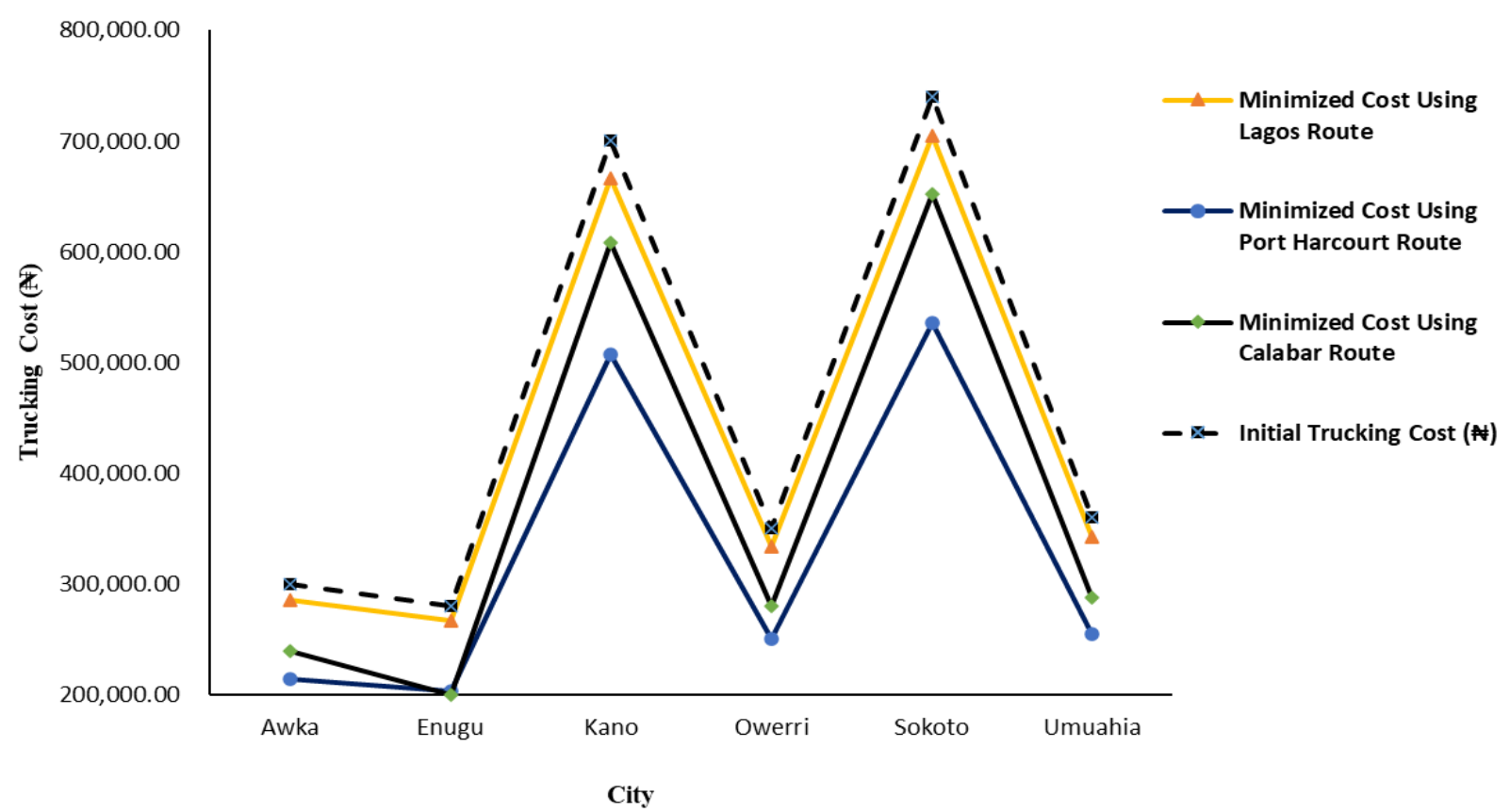

Fig. 3. Preferred Cities for Port Harcourt Distribution Outlet

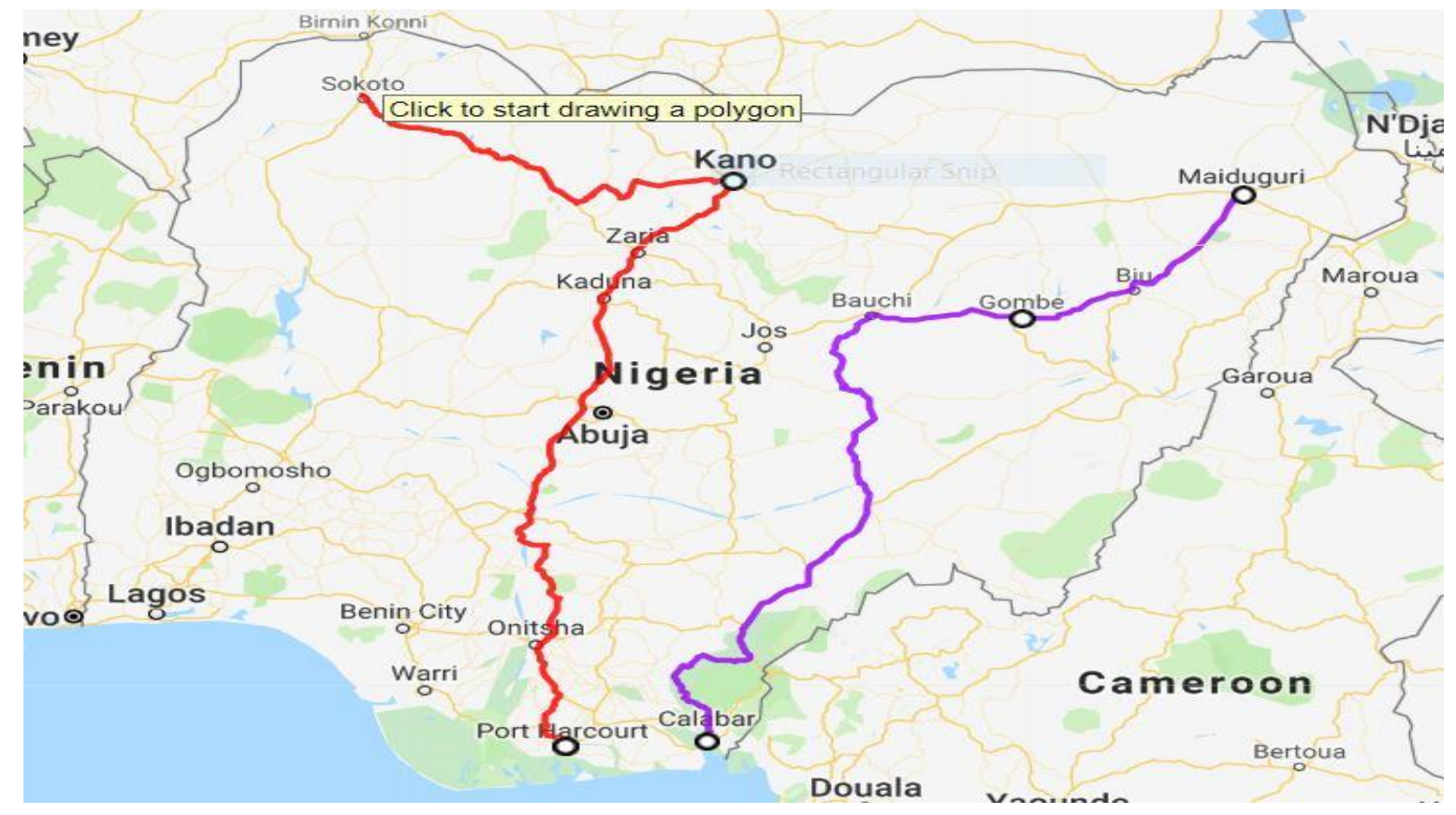

Fig. 4. Proposed distribution network using Port Harcourt and Calabar outlets

\section{CONCLUSION}

This study has developed a new cost-effective distribution network for LPG delivery to cities across Nigeria, using the proposed Port Harcourt and Calabar outlets, in addition to the existing Lagos outlet. The study also revealed that as much as an average of $25 \%$ reduction could be made in trucking costs across cities in the country if the proposed Port Harcourt and Calabar outlets are utilized for LPG distribution.

The cost of trucking LPG from the outlets mainly in the southern part of the country, to the cities in the Northern part of the country, is almost double the amount required for trucking the commodity to the towns in the southern part of the country. Consequently, to reduce the trucking cost to cities in the Northern part of Nigeria, the LPG production capacity from the Kaduna refinery should be ramped up to meet the demand of the commodity in that region. The supply from the refinery will bring down the trucking cost and hence the landing cost of LPG in the area., thereby contributing to the increased per capita consumption of the commodity. Alternatively, the proposed distribution outlets in this study should be utilized to reduce the cost of transporting LPG from Lagos to the northern cities of Nigeria.

The cost reductions in this study are for a unit LPG truck delivery. The savings from $x$ amount of trucks on a weekly, monthly, or annual delivery basis, can only be imagined. 


\section{APPENDIX A}

TABLE A1: DATA FOR MODEL DEVELOPMENT.

\begin{tabular}{lccc}
\hline City & $\begin{array}{c}\text { Distance } \\
\text { from Lagos } \\
\text { (Km) }\end{array}$ & Time (hrs) & $\begin{array}{c}\text { Trucking } \\
\text { Cost (\$) }\end{array}$ \\
\hline Akure & 314 & 5.00 & 135,000 \\
Awka & 501 & 7.22 & 300,000 \\
Bauchi & 1284 & 18.67 & 710,000 \\
Enugu & 560 & 9.15 & 280,000 \\
Gombe & 1291 & 18.40 & 700,000 \\
Ibadan & 139 & 2.50 & 106,000 \\
Kano & 1063 & 16.08 & 700,000 \\
Maiduguri & 1589 & 22.10 & 720,000 \\
Makurdi & 744 & 12.67 & 550,000 \\
Owerri & 534 & 8.12 & 350,000 \\
Port Harcour & 616 & 9.32 & 400,000 \\
Sokoto & 1782 & 29.00 & 750,000 \\
Umuahia & 577 & 9.38 & 360,000 \\
Uyo & 656 & 11.18 & 500,000 \\
\hline
\end{tabular}

Source: Kiakia gas [24].

\section{REFERENCES}

[1] Unipetrol. Analysis of seasonal mixtures: Propane-butane. Available: from unipetrol.com. 2015

[2] Speight, G.J. Natural Gas. A Basic Handbook. Gulf Publishing Company, Elsevier Inc., 2008.

[3] V. Ramanathan \& G. Carmichael (2008), Global and regional climate changes due to black carbon. Available: https://www.nature.com/articles/ngeo156.

[4] International Society for Environmental Epidemiology (ISEE) 2005. Annual Report.

[5] Kiakia gas. Retail LPG pricing in Nigeria. 2017. [online] Available: http://www.kiakiagas.com/blog/retail-lpg-pricing-nigeria

[6] World Liquefied Petroleum Gas Association Annual Report, 2015.

[7] KPMG. Domestic LPG market survey. 2015.

[8] O. U Oteh, N.M Agwu, E. N Nwaogu, and C. P Nto. Mitigating Climate Change and Determinants of Access to Liquefied Petroleum Gas (LPG) Among Urban Households in Abia State, Nigeria. J Earth Sci Clim Change 6: 276. 2015.doi:10.4172/2157-7617.1000276

[9] Houthakar and Talor. Surveys in applied economics: 1 model of consumer behavior. Available: https://www.district-energy.gr/en/energy-en/energy-sources-en/fossilfuels/liquefied-petroleum-gas/liquefied-petroleum-gas-market-analysi s/J. 1972.

[10] J. B Neeka, U., Ikoku, E., Iyalla, O., Joel, and S. Ikiensikimama, Predictive Models on Viable Options for Liquefied Petroleum Gas LPG Distribution: Case for a Small and Medium Scale Enterprise SME Commodity in Nigeria. Petroleum Technology Development Journal. 61[1]:61-75. 2019.

[11] A. I Ekejiuba, and C. U Ikoku. Viability of Producing LPG and LNG from the Nigerian Flare Gas Stream. 1990.
[12] Nwozuzu. Gas utilization in Nigeria. Problems and Prospects. Available:https://www.thisdaylive.com/index.php/2018/05/29/gas-pr oduction-and-utilisation-in-nigeria-problems-and-prospects/

[13] Cao, S. Michael, O and Brian, S.: Natural Gas Flare Reduction: Case Studies in Russia, Nigeria, and the United States. 2014

[14] S.T Apeh, K.B Erameh, and U Iruansi. Design and Development of Kitchen Gas Leakage Detection and Automatic Gas Shutoff System. Journal of Emerging Trends in Engineering and Applied Sciences (JETEAS) 5(3): 222-228. 2014

[15] I.A Papazolou and, O.N Aneziris Uncertainty quantification in the health consequences of the boiling liquid expanding vapor explosion phenomenon. Journal of Hazardous Materials 67(3): 217-235. 1999.

[16] D. F. Susan, K. H. Eckelmeyer \& A. C. Kilgo. Metallurgical failure analysis of a propane tank boiling liquid expanding vapor explosion (BLEVE). Journal of Failure Analysis and Prevention 5: 65-74. 2005.

[17] M. Alvin. Aerosol propellant. Available: www.brothersgas.com. 2016

[18] C. Woodford. Liquefied petroleum gas. Available: http://www.explainthatstuf. 2015.

[19] Y.T Shah. Chemical Energy from Natural and Synthetic Gas. CRC Press. 2017.

[20] A Demirbas. Fuel properties of hydrogen, liquefied petroleum gas (LPG), and compressed natural gas (CNG) for transportation; Energy Sources 24: 601-610. 2002

[21] D.K.B., Inkoom, and B.S. Biney. The potential of liquefied petroleum gas (LPG) as a viable energy option for the industrial sector in Ghana. Journal of Sustainable Development in Africa, 12(6), 34-61. 2010.

[22] H. Eric. How LPG is transported. Available: https://www.elgas.com.au/blog. 2018.

[23] K.A. Abdul-Kadir. Domestic LPG Market Growth -Infrastructura Challenges \& Opportunities. Available: http://nigerialpgas.com/downloads/Domestic_LPG_Market_Growth_I nfrastructural_Challenges_and_Opportunities.pdf 2017.

[24] Kiakia gas. Liquefied Petroleum Gas Transportation in Nigeria. 2019

IHEMTUGE, TOCHUKWU UZOMA holds a Master's degree in Petroleum and Gas Engineering (Gas Engineering option) from the University of Port Harcourt, Nigeria. $\mathrm{He}$ is a petroleum engineer-cum-entrepreneur with extensive experience in drilling, completion and remediation fluids, well-site operations (planning \& execution), coiled tubing \& workover operations

$\mathrm{He}$ is passionate about energy management, natural gas utilization and optimization, carbon reduction, and the provision of cleaner energy sources.

AIMIKHE, VICTOR JOSEPH holds a Ph.D. in Gas Engineering from the University of Port Harcourt, Nigeria. He is currently a lecturer at the Department of Petroleum and Gas Engineering, University of Port Harcourt, and the current deputy director, Center for Petroleum Research and Training, University of Port Harcourt.

His research focus is on Gas production, processing and transmission. He is also interested in the development of green materials for $\mathrm{CO}_{2}$ capture and storage. 